\title{
ApolipoproteinE $\varepsilon 4$ allelic variant, cognitive decline and psychosis in Alzheimer disease: a review of the literature and suggestions for upcoming studies
}

\author{
Ilaria Spoletini, BSc ${ }^{*}$ \\ Carlo Caltagirone, $\mathrm{MD}^{\star, * *}$ \\ Pietro Bria, MD*** \\ Gianfranco Spalletta, MD ${ }^{\star, \star *}$ \\ * IRCCS Santa Lucia Foundation, Rome \\ ** University of Rome "Tor Vergata", \\ Department of Neuroscience \\ *** Catholic University of the Sacred Hearth,
} Rome

ITALY

\begin{abstract}
Apolipoprotein E (ApoE) $\varepsilon 4$ allele represents a well known vascular risk factor for developing Alzheimer disease (AD) and differences in ApoE genotypes may explain a part of the variability in AD phenotypes. In fact, ApoE $\varepsilon 4$ allele possession seems to be associated with a more precocious age of onset, greater episodic memory impairment, and psychotic symptoms. The first question we discuss regards the role of ApoE $\varepsilon 4$ on cognitive progression of $\mathrm{AD}$. In fact, while a general agreement exists about the role played by ApoE $\varepsilon 4$ on the precocious onset of $\mathrm{AD}$, cognitive decline has been differently associated with ApoE $\varepsilon 4$ allele possession in AD patients in a continuum of faster decline, no effect, and slower decline. An attemptable interpretation is that the biological processes leading to the onset of $\mathrm{AD}$ are different from those involved in determining its clinical course. The second question regards the possible relationship between the presence of the degenerative pathological hallmarks of the disease in specific cerebral areas and different cognitive or behavioural symptoms. In fact, there is evidence that degenerative pathology in hippocampal formation and frontal cortex reflects the progression of cognitive deficits in brain aging and $\mathrm{AD}$ and that hypometabolism in right frontal lobe and greater frontal neuropsychological deficits occur in AD patients with psychosis in comparison to those without. The third question regards, specifically, the relationship between ApoE $\varepsilon 4$ variant and behavioural symptoms. In fact, there is evidence supporting the link between being carriers of ApoE $\varepsilon 4$ allele and severity of delusions, mostly at the early stage of the illness. In an interpretative challenge, we suggest that the link between being carriers of ApoE $\varepsilon 4$ allele and suffering from delusions in AD may be explained by frontal
\end{abstract}


lobe dysfunctions. Finally, we hypothesize that the most precocious onset of AD illness, described in carriers of ApoE $\varepsilon 4$ allelic variant, may also be related to the precocious onset of psychotic symptoms, which produces caregiver and patient distress and requires immediate assessment and treatment.

Received 20 December 2005

Accepted 26 January 2006

\section{Introduction}

Alzheimer's disease (AD) is a chronic neurodegenerative disorder that typically occurs after age 65, with incidence increasing concurrently with age. AD has a multidimensional clinical expression that manifests in three domains: a) neuropsychological deficits; b) functional impairment and c) behavioural disorders. In the diagnostic assessment process, neuropsychological and functional domains only are taken into consideration. On the contrary, behavioural and psychological symptoms of dementia (BPSD) are not mentioned in both DSM-IV and NINCDS-ARDRA criteria for diagnosis of AD. However, numerous studies demonstrated that BPSD are important components of dementia, contributing to both patient disability and caregiver distress (Cummings et al. 1994, Esiri 1996, Burns and Rabins 2000).

During the course of the illness, while cognitive impairment becomes more serious, BPSD seem to fluctuate, appearing either in the early or later phases of dementia (Jost \& Grossberg 1995, Jost \& Grossberg 1996, Cummings et al. 1998, Cummings \& Mendez 1997, Cummings 2003, Biswas et al. 2005). For example, psychotic symptoms seem to appear most frequently in a later phase of the disease (Schneider \& Dagerman 2004), depression is more severe in the precocious phase of the illness (Lyketsos \& Olin 2002, Lyketsos \& Lee 2004) and tends to improve in the latest stage (Cannon-Spoor et al. 2005), and apa- thy is the only BPSD that tends to worsen in direct correlation with the progression of global cognitive severity (Landes et al. 2005, Spalletta et al. 2004). These data suggest that cognitive and behavioural features are independent and heterogeneous dimensions, and that some BPSD may be the manifestation of specific dysfunctions, probably in specific cerebral areas. Since BPSD are heterogeneous dimensions that may fluctuate, occurring either in an early or in a late phase of dementia, we believe that it is important to consider the global cognitive level as a clinical index of neuropathological manifestation. In fact, different severity of global cognitive level and stage of AD pathology may be considered as confounding factors in BPSD studies.

Another issue regards the great pathogenetic variability of clinical characteristics in patients with $\mathrm{AD}$. In fact, research has focused on the identification of cardiovascular, inflammatory, biochemical, genetic and environmental risk factors of $\mathrm{AD}$ (Bossù et al. 2004, Chong \& Sahadevan 2005, Flirski \& Sobow 2005, Lee et al. 2005, Nowotny et al. 2005, Fujino et al. 2005, Kolsch et al. 2005, Bernardini et al. 2005). In particular, several studies focused on the role of vascular factors in the pathogenesis of AD (Derouesne 2005, Newman et al. 2005, Vogel et al. 2005, Hentschel et al. 2005).

Traditionally, AD (with frontotemporal dementia and Lewy body disease) is classified as a neurodegenerative type of demen- 
tia whereas other forms may be classified as vascular dementias since they seem to be associated with vascular risk factors. Despite this traditional classification, there is increasing evidence of the common role of haemostatic factors and inflammatory mechanisms in the pathogenesis of both vascular dementia and AD. In fact, many of the risk factors for cerebrovascular disease and vascular dementia, including serum total cholesterol, hypertension, atherosclerosis and Apolipoprotein E (ApoE) genotype, have also been shown to increase the risk of AD (Panza et al. 2005, Gupta et al., 2005). Furthermore, longitudinal studies demonstrated a significant increase in the risk of developing $\mathrm{AD}$ in cohorts of hypertensive patients compared to normotensive subjects, suggesting that extensive peripheral atherosclerosis is a risk factor for AD (Vogel et al. 2005, Newman et al. 2005). These findings are interesting but require confirmation. In fact, whereas there are some studies showing beneficial effects of antihypertensive drug use in reducing the risk of developing AD (Yasar et al. 2005, Qiu et al. 2005) and vascular dementia (in'tVeld et al. 2001), the potential benefit of preventive treatment with antihypertensive drugs in decreasing the risk of $\mathrm{AD}$ has not been confirmed in clinical trials (Lindsay et al. 2002, Morris et al. 2001). With the aim to explain these data, the hypothesis of the formation of a cerebrovascular disease that would combine with the neuropathological lesions typical of $\mathrm{AD}$ has been evoked, raising doubts on the diagnostic criteria used to define AD (Vogel et al. 2005).

Cardiovascular risk factors of $\mathrm{AD}$ are also linked to specific genetic polymorphisms, and some of these polymorphisms have been isolated. Papassotiropoulos and colleagues (Papassotiropoulos et al. 2005) evaluated whether clusters of cholesterol and lipid-related genetic variations were associated with $\mathrm{AD}$, identifying a cluster of polymorphisms. However, differences in genotypes may explain only a part of the variability in AD phenotypes, such as differences in age of onset, rapidity of cognitive decline and finally heterogeneity of BPSD. In fact, it is well known that AD can appear in sporadic and familial forms (Mayeux et al. 1985, Chiu et al. 1985, Rossor et al. 1984, Rossor et al. 1993), and the phenomenology of these two forms can be different in many features. In particular, the familial form of $\mathrm{AD}$ accounts for roughly 5-10\% of all cases worldwide, whereas the sporadic form of $\mathrm{AD}$ represents $90-95 \%$ of the remaining cases. The sporadic form is generally believed to be of late onset, occurring after 65 years of age, whereas the familial form is believed to be of early onset. Moreover, familial early onset AD and sporadic late onset $\mathrm{AD}$ seem to have differences in clinical and neuropsychological manifestations. Studies found that patients with early onset AD had more aphasia, and a shorter duration of illness than patients with late onset AD (Lampe et al. 1994, Haltia et al. 1994). Other studies reported that AD patients with familial aggregation compared with sporadic cases had more marked impairment of language, praxia, and graphia (Breitner \& Folstein 1984). Finally, some genetic factors, underlying the pathogenesis of early onset AD (Zekanowski et al. 2004, Lehtovirta et al. 1996, Reiss et al. 2005, Mosconi et al. 2005) and late onset AD (Olin et al. 2005, Bernardini et al. 2005, Liang et al. 2005, Strittmatter et al. 1993, Saunders et al. 1993), have been identified.

Thus, neuropathological and genetic findings associated with the different forms of AD may explain different clinical manifestations (Lahiri et al. 2004). In particular, in this review we will focalize on an allelic 
variant, named ApoE $\varepsilon 4$, that seems to influence the risk and age of onset of AD and to have a selective effect on episodic memory decline (Wilson et al. 2002; Mayeux et al. 2001) and some behavioural symptoms. ApoE \&4 seems to be related with the clinical manifestations of $\mathrm{AD}$ through an association with the pathologic hallmarks of disease (neuritic plaques, diffuse plaques, and neurofibrillary tangles) rather than some other mechanisms (e. g., direct effect on neuronal survival) (Bennett et al. 2003b). In addition, in transgenic animal studies, ApoE \&4 allelic variant causes neuropathology and behavioral deficits (Holtzman et al. 2000).

In order to clarify the status quo of the relationship between ApoE $\varepsilon 4$ allelic variant possession, cognitive decline and psychotic manifestations in AD patients, we conducted detailed searches of the published medical literature with a review of the Medline (PubMed) databases. For our searches we used various combinations of the following keywords: "apoe”, "Alzheimer", “psychosis", "delusion", "hallucination", "cognitive decline", "onset", "BPSD”. The articles highlighted in our searches spanned the years 1992-2005 and include all of the important literature pertaining to the relationship between ApoE \&4 allele possession, psychotic symptoms and cognitive features in Alzheimer's disease. For each citation identified, we scanned titles or abstracts, or both. We searched bibliographies of published articles for relevant titles. We selected English language only. Cross-references and review articles were used for search completion. If such data were available for only a subset of patients, this subset was included. In studies reporting repeatedly on the same study population, only the most recent study was included.

\section{The effect of ApoE $\varepsilon 4$ on cognitive impairment}

ApoE $\varepsilon 4$ allele variant possession represents one well known vascular risk factor for developing $\mathrm{AD}$. ApoE is a plasmatic lipoprotein involved in cholesterol transference, secreted in the central nervous system by astrocytes. ApoE is a polymorphic 299aminoacid protein, coded by a gene that is allocated on chromosome 19, and has three allelic variants named $\varepsilon 2, \varepsilon 3, \varepsilon 4$. These isoforms differ from one another at residues 112 and 158. ApoE $\varepsilon 3$ has cysteine at position 112 and arginine at position 158, ApoE $\varepsilon 4$ has arginine at both positions, and ApoE $\varepsilon 2$ has cysteine at both positions. In almost all populations, the $\varepsilon 3$-allele accounts for the vast majority of the ApoE gene pool (typically $70-80 \%$ ) and the $\varepsilon 4$ and $\varepsilon 2$ alleles account for $10-15 \%$ and $5-10 \%$ of the population, respectively (Roses 1996). There is evidence that subject carriers of ApoE \&4 allele have higher levels of total and low density lipoprotein cholesterol and a higher risk for myocardial infarction and coronary heart disease than non-carriers of the $\varepsilon 4$ allele (Utermann et al. 1984, Menzel et al. 1983). Several studies suggested that $\varepsilon 4$ allele is associated with an increased risk of developing $\mathrm{AD}$ in both early onset familial and sporadic forms of the illness (Farrer et al. 1997, Bullido et al. 1998, Slooter et al. 1998, Mayeux et al. 1993). In this direction, a study by Hsiung et al. (2004) investigated the effect of ApoE $\varepsilon 4$ on predicting conversion from normal to "cognitive impairment, no dementia" (CIND) to AD, finding that the ApoE $\varepsilon 4$ genotype was a significant risk factor in the conversion from CIND to AD and from normal to $\mathrm{AD}$ and vascular dementia. In the same study, ApoE $\varepsilon 4$ allele possession was associated with a decrease in age of onset. In fact, in the literature there 
is evidence that $\mathrm{ApoE} \varepsilon 4$ allele possession is associated with a more precocious age of onset (Reiss et al. 2005, Mosconi et al. 2005, Roses 1994, Lopez et al. 1997), and several studies investigated its influence on determining the severity of memory disorder (Bondi et al. 1995, O'Hara et al. 1998, Mayeux et al. 2001). Some research hypothesizes that presence and amount of ApoE $\varepsilon 4$ alleles are predictors of impairment in cognitive performances (Nacmias et al. 2004). In particular, the presence of ApoE $\varepsilon 4$ allele seems to affect the memory in the early stage of dementia, so both normal control and patients with dementia carriers ApoE $\varepsilon 4$ allele show a more severe memory impairment and mild verbal involvement (Bondi et al. 1995, O'Hara et al. 1998, Nagy et al. 1995, Wilson et al. 2002). In this field, Marra and colleagues (2004) found that AD patient carriers of ApoE $\varepsilon 4$ allele were characterized by a different neuropsychological pattern at the onset of the illness compared to $\mathrm{AD}$ patient non-carriers of ApoE $\varepsilon 4$ allele. However, in the sample with early onset AD (i.e. age of onset under 65) only this effect was significant. Moreover, patients with early onset $\mathrm{AD}$ carriers of ApoE \&4 allele showed worse performances in learning, long-term verbal memory and general intelligence tasks compared to late onset $\mathrm{AD}$ patients carriers of ApoE $\varepsilon 4$ allele. Thus, in patients with late onset $\mathrm{AD}$, the pattern of cognitive impairment at the onset does not seem to be dependent on the possession of an $\varepsilon 4$ allele in the genotype. This difference could be due to distinct pathogenic mechanisms between the onset and the course of AD (Marra et al. 2004).

While a general agreement seems to exist on the role played by ApoE $\varepsilon 4$ allelic variant both at the onset of AD (Slooter et al. 1998, Saunders et al. 1993) and on the rate of brain atrophy (Wahlund et al. 1999), the effect on the cognitive progression of $\mathrm{AD}$ during the course of the illness is still controversial. From a mere neuro-pathological point of view, since there is evidence that ApoE $\varepsilon 4$ allelic variant works through betaamyloid deposition in senile plaques and neurofibrillary tangles (Bennett et al. 2005, Bennett et al. 2003a, Namba et al. 1991, Wisniewski \& Frangione 1992), which are the neuropathogenetic hallmark of cognitive impairment and seem to be associated with disease progression, ApoE $\varepsilon 4$ allele possession should be linked to the rate of cognitive decline (Plassman \& Breitner 1996). In reality, in the clinical setting the cognitive decline of AD patients has been differently associated with ApoE $\varepsilon 4$ allele possession in a continuum of faster decline (Adak et al. 2004, Craft et al. 1998, Bondi et al. 1999), no effect (Murphy et al. 1997, Dal Forno et al. 1996, Kurz et al. 1996, Growdon et al. 1996), and slower decline (Hoyt et al. 2005, Frisoni et al. 1995, Stern et al. 1997).

A hypothesis that may explain these discordant data is that the biological processes that lead to the $\mathrm{AD}$ onset are different from those involved in determining its clinical course. In fact, while there is evidence that ApoE $\varepsilon 4$ works through beta-amyloid deposition in senile plaques, cognitive impairment has not been found to correlate with plaque density but rather with synaptic and neuronal loss and number of neurofibrillary tangles (Arriagada et al. 1992, Terry et al. 1991, Terry 2000). Thus, neuronal and synaptic loss are mixed in the AD brain and correlate differently with disease progression (Gomez-Isla et al. 1997, West 1993, Kril et al. 2002, Davies et al. 1987, Masliah et al. 1991, Heinonen et al. 1995, Hansen et al. 1998). A study by Ingelsson et al. (2004) confirms that the duration of dementia correlates with the degree of neurofibrillary tangles and synaptic loss, but not with amy- 
loid plaques in the AD brain. In addition, with the increasing of disease severity, progressive numbers of neurofibrillary tangles occur in hippocampus, enthorinal cortex, and high-order association cortices (Arriagada et al. 1992, Gomez-Isla et al. 1997, Riley et al. 2002, Guillozet et al. 2003), frontal lobe among the others (Giannakopoulos et al. 2003). On the contrary, amyloid plaques seem to have a more widespread anatomic distribution in the AD brain (Braak \& Braak 1991, Arnold et al. 1991) and the extent of amyloid deposition tends to correlate poorly with AD symptoms and severity (Braak \& Braak 1991, GomezIsla et al. 1997, Giannakopoulos et al. 2003, Guillozet et al. 2003). Indeed, amyloid accumulation increases in AD patients irrespective of disease duration. These data seem to suggest that there are distinct processes involved in the initiation and progression of $\mathrm{AD}$ pathology. On the other hand, morphologic and biochemical studies have challenged this point of view (Cummings et al. 1996, Naslund et al. 2000). Thus, this question remains open and one may wonder if these previous mixed results on the course of cognitive deterioration of AD patients were influenced by a different distribution of related genotypes in ApoE \&4 carriers and non-carriers. In addition, a confounding effect of other variables, such as the response to medical treatment, rehabilitation therapy and, most at all, different stages of progression at baseline, could account for the evolution in the later stages.

Another issue regards the relationship between brain pathology of different types and the specific cerebral areas in which this damage occurs, as high-order association cortices or others. An important question is if this damage in specific cerebral areas is linked with different cognitive symptoms or BPSD. For example, there is evidence that pathology in hippocampal formation and frontal cortex (area 9) reflects the progression of cognitive deficits in brain aging and AD (Giannakopoulos et al. 2003) and that right frontal hypometabolism (Sultzer et al. 1995) and greater frontal neuropsychological deficits (Jeste et al. 1992) occur in AD patients with psychosis in comparison to those without.

\section{The effect of ApoE on psychotic symptoms}

Several studies explored the relationship between ApoE $\varepsilon 4$ allelic variant and BPSD in $\mathrm{AD}$, since there is evidence that this variant may influence the behavioural manifestations of AD. These studies achieved different and controversial conclusions, most of all about the relationship between ApoE $\varepsilon 4$ and psychotic symptoms (Scarmeas et al. 2002).

A study by Ramachandran et al. (1996) examined the relationship between ApoE genotype and depressive/psychotic manifestations in patients with $\mathrm{AD}$, evaluating them as both continuous and categorical variables. Subjects with AD carriers of ApoE $\varepsilon 4$ allelic variant had greater severity of depression and psychotic symptoms. An attemptable interpretation is that genotype ApoE $\varepsilon 4$, affecting properties of beta-amyloid or neurofibrillary tangles, could create a predisposition to develop behavioural symptoms in patients with AD (Roses 1994). In fact, AD patients with psychotic symptoms have an increased number of senile plaques and neurofibrillary tangles in the encephalon. In particular, the senile plaques are more widespread in the presubiculum, and the neurofibrillary tangles in the medial frontal cortex (Ramachandran et al. 1996). These 
results have been successively confirmed by Ballard et al. (1997) and by Harwood et al. (1999). However, there are controversial data. Indeed, Lopez et al. (1997) did not find any association between ApoE $\varepsilon 4$ and major depression or psychotic symptoms. In addition, Lyketsos et al. (1997) did not find any statistical significant association between ApoE \&4 allelic variant and delusions, hallucinations or depression, and concluded that ApoE $\varepsilon 4$ cannot be considered a risk factor for developing behavioural symptoms in AD. Hirono et al. (1998) found delusions or hallucinations in $51 \%$ of their sample in association with advanced age, female gender, longer length of illness, greater cognitive impairment, but not with ApoE \&4 allelic variant. Levy et al. (1999) did not find significant differences between patient carriers of ApoE $\varepsilon 4$ allele and patient non-carriers of ApoE $\varepsilon 4$ allele in any behavioural variable. However, since subjects in this study were affected by different levels of severity of $\mathrm{AD}$, the same authors suggest that the effect of ApoE $\varepsilon 4$ could differently contribute to the development of behavioural symptoms in different phases of dementia. Therefore, longitudinal studies may be more valid in this field but only recently this kind of methodology has been applied. Scarmeas et al. (2002) conducted a longitudinal study finding a strong association between number of ApoE $\varepsilon 4$ alleles and frequency of delusions. On the contrary, the presence of both ApoE $\varepsilon 4$ alleles was significantly but weakly associated with a lower risk to develop hallucinations. Finally, there was no association with depressive symptoms or other BPSD. Another longitudinal study, by Chang et al. (2004), analyzing the predictive value of ApoE $\varepsilon 4$ allele in developing psychiatric symptoms, found that psychotic symptoms were more frequent in AD patients carrying ApoE $\varepsilon 4$ allele. They hypothesized that the reason for these results could be linked to a massive decrease in the cholinergic activity (Chang et al. 2004, Soininen et al. 1995).

\section{An interpretative challenge}

How we can explain the inconsistent and contrasting results on the relationship between being carriers of ApoE $\varepsilon 4$ allelic variant and psychotic symptoms? As we have seen, they may probably be attributed to methodological flaws. Indeed, studies on this issue used different methods and samples are not comparable by phase of illness, so a further variability is linked to the different length and severity of dementia. The principal limitation of these studies is that they examine the frequency of symptoms without considering how a patient is situated in the course of dementia (Scarmeas et al. 2002). Moreover, 1) some of these studies are based on small samples, having low statistic power; 2) they use different criteria or guidelines for the diagnosis of AD and, in particular, dissimilar definitions of psychotic symptoms or syndromes; 3 ) most of the studies do not consider interactions between factors (Hirono et al. 1998) and there is no control for confounding factors; 4) all the studies on the relationship between ApoE $\varepsilon 4$ and psychotic symptoms published until 2002 have a cross-sectional experimental design, and this strongly limits the possibility of an interpretation of causal relationships between factors (Chang et al. 2004); and finally 5) another issue regards the distinction between hallucinations and delusions. In fact, almost all the studies consider psychosis as a whole and undifferentiated phenomenon.

In a recent study, Spalletta et al. (2005) analysed the relationship between the entire 
range of BPSD, cognitive deficit, sociodemographic characteristics, and ApoE $\varepsilon 4$ allele possession in $\mathrm{AD}$ patients with late onset. They found that the ApoE $\varepsilon 4$ allele possession was associated with an increased level of delusions within the month preceding the first examination, and with the presence of categorical delusions at the early stage until the first examination. Furthermore, at the early stage of the illness, the relationship between ApoE $\varepsilon 4$ allele and behavioural symptoms was confirmed for delusions only. These results confirm data of the longitudinal study of Scarmeas et al. (2002). It is important to underline that in the Spalletta et al. (2005) study the level of delusions in $\mathrm{AD}$ patients carrying $\mathrm{ApoE} \varepsilon 4$ allele within the month of the first examination was exactly twice as much as the level found in patients who did not carry the ApoE $\varepsilon 4$ allele. In addition, frequency of patients with clinically significant categorical delusions having the ApoE $\varepsilon 4$ allele was more than twice as much as the frequency of patients who did not carry the ApoE $\varepsilon 4$ allele.

Considering that patients with delusions have different cerebral functional abnormalities in comparison to patients with hallucinations (Kotrla et al. 1995, Lopez et al. 2001), that patients with hallucinations may have specific cerebral atrophy (Holroyd et al. 2000), and that patients with delusions have, among the others, frontal lobe dysfunction (Staff et al. 1999, Lopez et al. 2001, Sultzer et al. 2003), in a challenge to interpret these above-mentioned results we suggest that the link between being carriers of ApoE $\varepsilon 4$ allele and suffering from delusions in AD is related to frontal lobe dysfunction. In addition, cerebral functional abnormalities (Hogh et al. 2001, Sakamoto et al. 2003, Mosconi et al. 2004) and abnormalities in cholinergic neurons (Soininen $e t$ al. 1995, Soininen \& Riekkinen 1996) in the frontal areas have been described in association with ApoE $\varepsilon 4$ allele possession. In fact, some neuroimaging studies found that psychotic symptoms in AD correlated with hypometabolic abnormalities in the right frontal cortex (Sultzer et al. 1995) and an association between psychosis in $\mathrm{AD}$ and hypoperfusion in frontal lobes was reported using SPECT (Mega et al. 2000). Another study found that delusions were related to hypometabolism, particulary in the right superior dorsal lateral cortex and anterior cingulate, and that hypometabolism in the right inferior frontal pole and orbital frontal areas correlated with clinical severity of delusions (Sultzer et al. 2003). In addition, patients with psychotic symptoms have greater frontal lobe and executive function neuropsychological deficits than $\mathrm{AD}$ patients with psychosis. A study by Jeste et al. (1992) found that delusional $\mathrm{AD}$ patients had more impairment in conceptualisation and verbal fluency tasks, that require frontal function, than non delusional patients. Thus, our hypothesis seems to be supported by convergent data indicating frontal lobe dysfunctions in delusional $\mathrm{AD}$ patients.

\section{Suggestions for upcoming studies}

After a review of the literature about the issue of the relationship between ApoE genotypes, cognitive features and psychotic symptoms in $\mathrm{AD}$ patients, the main question that arises regards the methodological flaws affecting most of the studies we report. A suggestion for the upcoming research is to consider how patients are situated in the course of dementia, so that different studies could be comparable, having eliminated the 
variability linked to the different phase of illness and different severity of global cognitive decline and possibly neuropathology. The question of the relationship between ApoE \&4 allele possession and psychotic symptoms requires a longitudinal experimental design, that permits to follow patients during time and extend the possibility of interpretations of casual relationships between factors. Since some of the studies we report are based on small samples, another methodological guideline regards the importance of using more numerous samples with the aim to increase statistical power. The third methodological issue regards the necessity to standardize criteria used for the diagnosis of psychotic symptoms. In order to resolve this important limit, we suggest using criteria that have been elaborated by Jeste \& Finkel (Biswas et al. 2005). On the basis of these specific guidelines, to diagnose psychosis in $\mathrm{AD}$ the following criteria must be fulfilled: presence of one (or more) of the visual or auditory hallucinations or delusions (criterion A); DSM-IV and NINCDS-ARDRA criteria for the diagnosis of AD (criterion $\mathrm{B}$ ); evidence from the history that symptoms in criterion A have not been present continuously prior to the onset of dementia (criterion C); symptoms in criterion A must be present, at least intermittently, for 1 month or longer during the course of the illness and be severe enough to cause some disruption in patients' and/or others' functioning (criterion D); mood disorder with psychotic features that have never been met (criterion E); the disturbance does not occur exclusively during the course of a delirium (criterion F); the disturbance is not better accounted for by another general-medical condition or direct physiological effects of a substance (e.g., a drug of abuse, a medication) (criterion $\mathrm{G})$. In addition, it is possible to specify if there are associated features such as agita- tion (when there is evidence, from history or examination, of prominent agitation with or without physical or verbal aggression); negative symptoms (when prominent negative symptoms, such as apathy, affective flattening, avolition, or motor retardation, are present); depression (when prominent depressive symptoms, such as depressed mood, insomnia or hypersomnia, feelings of worthlessness or excessive or inappropriate guilt, or recurrent thoughts of death, are present).

Since recent studies have demonstrated the presence of a specific association between ApoE $\varepsilon 4$ allele possession and delusions (Spalletta et al. 2005, Scarmeas et al. 2002) the last methodological suggestion regards the importance of operating a distinction between hallucinations and delusions and between misidentification and paranoid delusions, and not to consider psychosis as a whole and undifferentiated phenomenon. Neuroimaging (Spalletta et al. 2005) and phenomenological (Perez-Madrinan et al. 2004) data confirm this idea.

The upcoming research will probably be focused on the relationship between ApoE $\varepsilon 4$ and psychotic symptoms also in the precocious phase of dementia.

\section{Conclusions}

We believe that the issue of the relationship between ApoE \&4 allelic variant and behavioural symptoms in $\mathrm{AD}$ is very interesting and needs to be accurately investigated, because it can be useful, in conjunction with other clinical and pathogenetic characteristics, for an early detection of dementia even before the onset of cognitive impairment. 
Finally, we hypothesize that the most precocious onset of $\mathrm{AD}$ illness, described in carriers of ApoE $\varepsilon 4$ allelic variant, may also be related to the precocious onset of psychotic symptoms, which produces caregiver and patient distress, requires immediate assessment and treatment, and facilitate early diagnosis.

\section{References}

Adak S, Illouz K, Gorman W, et al. Predicting the rate of cognitive decline in aging and early Alzheimer disease. Neurology 2004, 13; 63 (1): 108-114.

Arnold S, Hyman BT, Flory J, et al. The topographical and neuroanatomical distribution of neurofibrillary tangles and neuritic plaques in the cerebral cortex of patients with Alzheimer's disease. Cereb Cortex 1991;1(1): 103-116.

Arriagada PV, Growdon JH, Hedley-Whyte ET, Hyman BT. Neurofibrillary tangles but not senile plaques parallel duration and severity of Alzheimer's disease. Neurology 1992; 42(3 Pt 1): 631-639.

Ballard C, Massey H, Lamb H, Morris C. Apolipoprotein E: non-cognitive symptoms and cognitive decline in late onset Alzheimer's disease. J Neurol Neurosurg Psychiatry 1997; 63(2): 273.

Bennett DA, Schneider JA, Wilson RS, Bienias JL, Berry-Kravis E, Arnold SE. Amyloid mediates the association of apolipoprotein E e4 allele to cognitive function in older people. J Neurol Neurosurg Psychiatry 2005; 76(9): 1194-1199.

Bennett DA, Wilson RS, Schneider JA et al. Apolipoprotein E epsilon4 allele, AD pathology, and the clinical expression of Alzheimer's disease. Neurology 2003; 60(2): 246-252.

Bennett DA, Wilson RS, Schneider JA et al. Education modifies the relation of AD pathology to level of cognitive function in older persons. Neurology 2003; 60(12): 19091915.

Bernardini S, Bellincampi L, Ballerini S et al. Glutathione S-transferase P1 *C allelic variant increases susceptibility for late-onset Alzheimer disease: association study and relationship with apolipoprotein E epsilon4 allele. Clin Chem 2005; 51(6): 944-951.

Bondi MW, Salmon DP, Galasko D, Thomas RG, Thal LJ. Neuropsychological function and apolipoprotein E genotype in the preclinical detection of Alzheimer's disease. Psychol Aging 1999; 14(2): 295-303.

Bondi MW, Salmon DP, Monsch AU et al. Episodic memory changes are associated with the APOE-epsilon 4 allele in nondemented older adults. Neurology 1995; 45(12): 2203-2206

Bossù $\mathrm{P}$, Ciaramella $\mathrm{A}$, Moro ML, et al. Alzheimer's disease and immune activation: a translational perspective. Neurosci Res Communications 2004; 35: 193-201.

Braak H, Braak E. Neuropathological stageing of Alzheimer-related changes. Acta Neuropathol (Berl) 1991; 82(4): 239-259.

Breitner JC, Folstein MF. Familial Alzheimer Dementia: a prevalent disorder with specific clinical features. Psychol Med 1984; 14(1): 63-80.

Bullido MJ, Artiga MJ, Recuero M, et al. A polymorphism in the regulatory region of APOE associated with risk for Alzheimer's dementia. Nat Genet 1998; 18(1): 6971.

Burns A. The burden of Alzheimer's disease. Int $J$ Neuropsychopharmacol 2000; 3(7): 31-38.

Cannon-Spoor HE, Levy JA, Zubenko GS et al. Effects of previous major depressive illness on cognition in Alzheimer disease patients. Am J Geriatr Psychiatry 2005; 13(4): 312-318.

Chang JB, Wang PN, Chen WT, et al. ApoE epsilon4 allele is associated with incidental hallucinations and delusions in patients with AD. Neurology 2004; 63(6): 11051107.

Chong MS, Sahadevan S. Preclinical Alzheimer's disease: diagnosis and prediction of progression. Lancet Neurol 2005; 4(9): 576-579.

Chui HC, Teng EL, Henderson VW, Moy AC. Clinical subtypes of dementia of the Alzheimer type. Neurology 1985; 35(11): 1544-1550.

Craft S, Teri L, Edland SD et al. Accelerated decline in apolipoprotein E-epsilon4 homozygotes with Alzheimer's disease. Neurology 1998; 51(1): 149-153.

Cummings BJ, Pike CJ, Shankle R, Cotman CW. Betaamyloid deposition and other measures of neuropathology predict cognitive status in Alzheimer's disease. Neurobiol Aging 1996; 17(6): 921-933.

Cummings JL, Mega M, Gray K, Rosenberg-Thompson S, Carusi DA, Gornbein J. The Neuropsychiatric Inventory: comprehensive assessment of psychopathology in dementia. Neurology 1994; 44(12): 845-861.

Cummings JL. Cognitive and behavioral heterogeneity in Alzheimer's disease: seeking the neurobiological basis. Neurobiol Aging 2000; 21(6): 2308-2314. 
Dal Forno G, Rasmusson DX, Brandt $\mathrm{J}$ et al. Apolipoprotein E genotype and rate of decline in probable Alzheimer's disease. Arch Neurol 1996; 53(4): 345-350.

Davies CA, Mann DM, Sumpter PQ, Yates PO. A quantitative morphometric analysis of the neuronal and synaptic content of the frontal and temporal cortex in patients with Alzheimer's disease. J Neurol Sci 1987; 78(2): 151164.

Derouesne C. [Vascular dementia: the dubious disease]. Psychol Neuropsychiatr Vieil 2005; 3(2): 89-96.

Esiri MM. The basis for behavioural disturbances in dementia. J Neurol Neurosurg Psychiatry 1996; 61(2): 127-130.

Farrer LA, Cupples LA, Haines JL et al. Effects of age, sex, and ethnicity on the association between apolipoprotein E genotype and Alzheimer disease. A meta-analysis. APOE and Alzheimer Disease Meta Analysis Consortium. JAMA 1997; 278(16): 1349-1356.

Flirski M, Sobow T. Biochemical markers and risk factors of Alzheimer's disease. Curr Alzheimer Res 2005; 2(1): 47-64.

Frisoni GB, Govoni S, Geroldi C et al. Gene dose of the epsilon 4 allele of apolipoprotein $\mathrm{E}$ and disease progression in sporadic late-onset Alzheimer's disease. Ann Neurol 1995; 37(5): 596-604.

Fujino Y, Wang DS, Thomas N, Espinoza M, Davies P, Dickson DW. Increased frequency of argyrophilic grain disease in Alzheimer disease with $4 \mathrm{R}$ tau-specific immunohistochemistry. J Neuropathol Exp Neurol 2005; 64(3): 209-214.

Giannakopoulos P, Herrmann FR, Bussiere T et al. Tangle and neuron numbers, but not amyloid load, predict cognitive status in Alzheimer's disease. Neurology 2003; 60(9): 1495-500.

Gomez-Isla T, Hollister R, West $\mathrm{H}$ et al. Neuronal loss correlates with but exceeds neurofibrillary tangles in Alzheimer's disease. Ann Neurol 1997; 41(1): 17-24.

Growdon JH, Locascio JJ, Corkin S, Gomez-Isla T, Hyman BT. Apolipoprotein E genotype does not influence rates of cognitive decline in Alzheimer's disease. Neurology 1996; 47(2): 444-448.

Guillozet AL, Weintraub S, Mash DC, Mesulam MM. Neurofibrillary tangles, amyloid, and memory in aging and mild cognitive impairment. Arch Neurol 2003; 60(5): 729736.

Gupta A, Watkins A, Thomas P et al. Coagulation and inflammatory markers in Alzheimer's and vascular dementia. Int J Clin Pract 2005; 59(1): 52-57.
Haltia M, Viitanen M, Sulkava R et al. Chromosome 14encoded Alzheimer's disease: genetic and clinicopathological description. Ann Neurol 1994; 36(3): 362-367.

Hansen LA, Daniel SE, Wilcock GK, Love S. Frontal cortical synaptophysin in Lewy body diseases: relation to Alzheimer's disease and dementia. J Neurol Neurosurg Psychiatry 1998; 64(5): 653-656.

Harwood DG, Barker WW, Ownby RL, St George-Hyslop P, Duara R. Apolipoprotein-E (APO-E) genotype and symptoms of psychosis in Alzheimer's disease. Am J Geriatr Psychiatry 1999; 7(2): 119-123.

Heinonen O, Soininen H, Sorvari $\mathrm{H}$ et al. Loss of synaptophysin-like immunoreactivity in the hippocampal formation is an early phenomenon in Alzheimer's disease. Neuroscience 1995 ; 64(2): 375-384.

Hentschel F, Supprian T, Frolich L. [Alzheimer's disease versus vascular dementia -- dichotomy or interaction?]. Fortschr Neurol Psychiatr 2005; 73(6): 317-326.

Hirono N, Mori E, Yasuda M et al. Factors associated with psychotic symptoms in Alzheimer's disease. J Neurol Neurosurg Psychiatry 1998; 64(5): 648-652.

Hogh P, Knudsen GM, Kjaer KH, Jorgensen OS, Paulson OB, Waldemar G. Single photon emission computed tomography and apolipoprotein $\mathrm{E}$ in Alzheimer's disease: impact of the epsilon 4 allele on regional cerebral blood flow. J Geriatr Psychiatry Neurol 2001; 14(1): 42-51.

Holroyd S, Shepherd ML, Downs JH 3rd. Occipital atrophy is associated with visual hallucinations in Alzheimer's disease. J Neuropsychiatry Clin Neurosci 2000; 12(1): 25-28.

Holtzman DM, Bales KR, Tenkova T et al. Apolipoprotein $\mathrm{E}$ isoform-dependent amyloid deposition and neuritic degeneration in a mouse model of Alzheimer's disease. Proc Natl Acad Sci U S A 2000; 97(6): 2892-2897.

Hoyt BD, Massman PJ, Schatschneider C, Cooke N, Doody RS. Individual growth curve analysis of APOE epsilon 4-associated cognitive decline in Alzheimer disease. Arch Neurol 2005; 62(3): 454-459.

Hsiung GY, Sadovnick AD, Feldman H. Apolipoprotein E epsilon4 genotype as a risk factor for cognitive decline and dementia: data from the Canadian Study of Health and Aging. CMAJ 2004; 171(8): 863-867.

Ingelsson M, Fukumoto H, Newell KL et al. Early Abeta accumulation and progressive synaptic loss, gliosis, and tangle formation in AD brain. Neurology 2004; 62(6): 407-412.

in't Veld BA, Ruitenberg A, Hofman A, Stricker BH, Breteler MM. Antihypertensive drugs and incidence of dementia: the Rotterdam Study. Neurobiol Aging 2001; 22(3): 925-931. 
Jeste DV, Finkel SI. Psychosis of Alzheimer's disease and related dementias. Diagnostic criteria for a distinct syndrome. Am J Geriatr Psychiatry 2000; 8(1): 29-34.

Jeste DV, Wragg RE, Salmon DP, Harris MJ, Thal LJ. Cognitive deficits of patients with Alzheimer's disease with and without delusions. Am J Psychiatry 1992; 149(2): 184-189.

Jost BC, Grossberg GT. The evolution of psychiatric symptoms in Alzheimer's disease: a natural history study. $J$ Am Geriatr Soc 1996; 44(9): 1078-1081.

Kolsch H, Jessen F, Freymann N et al. ACE I/D polymorphism is a risk factor of Alzheimer's disease but not of vascular dementia. Neurosci Lett 2005; 377(1): 37-39.

Kotrla KJ, Chacko RC, Harper RG, Jhingran S, Doody R. SPECT findings on psychosis in Alzheimer's disease. Am J Psychiatry 1995; 152(10): 1470-1475.

Kril JJ, Patel S, Harding AJ, Halliday GM. Neuron loss from the hippocampus of Alzheimer's disease exceeds extracellular neurofibrillary tangle formation. Acta Neuropathol (Berl) 2002; 103(4): 370-376.

Kurz A, Egensperger R, Haupt $\mathrm{M}$ et al. Apolipoprotein E epsilon 4 allele, cognitive decline, and deterioration of everyday performance in Alzheimer's disease. Neurology 1996; 47(2): 440-443.

Lahiri DK, Sambamurti K, Bennett DA. Apolipoprotein gene and its interaction with the environmentally driven risk factors: molecular, genetic and epidemiological studies of Alzheimer's disease. Neurobiol Aging 2004; 25(5): 651-660.

Lampe TH, Bird TD, Nochlin D et al. Phenotype of chromosome 14-linked familial Alzheimer's disease in a large kindred. Ann Neurol 1994; 36(3): 368-378.

Landes AM, Sperry SD, Strauss ME. Prevalence of apathy, dysphoria, and depression in relation to dementia severity in Alzheimer's disease. J Neuropsychiatry Clin Neurosci 2005; 17(3): 342-349.

Lee J, Fukumoto H, Orne J et al. Decreased levels of BDNF protein in Alzheimer temporal cortex are independent of BDNF polymorphisms. Exp Neurol 2005; 194(1): 91-96.

Lehtovirta M, Soininen H, Helisalmi S et al. Clinical and neuropsychological characteristics in familial and sporadic Alzheimer's disease: relation to apolipoprotein $\mathrm{E}$ polymorphism. Neurology 1996; 46(2): 413-419.

Levy ML, Cummings JL, Fairbanks LA, Sultzer DL, Small GW. Apolipoprotein E genotype and noncognitive symptoms in Alzheimer's disease. Biol Psychiatry 1999; 45(4): 422-425.

Liang X, Schnetz-Boutaud N, Kenealy SJ, et al. Covariate analysis of late-onset Alzheimer disease refines the chromosome 12 locus. Mol Psychiatry 2005. [published online Oct 11, 2005].

Lindsay J, Laurin D, Verreault R et al. Risk factors for Alzheimer's disease: a prospective analysis from the Canadian Study of Health and Aging. Am J Epidemiol 2002; 156(5): 445-453.

Lopez OL, Kamboh MI, Becker JT, Kaufer DI, DeKosky ST. The apolipoprotein E epsilon 4 allele is not associated with psychiatric symptoms or extrapyramidal signs in probable Alzheimer's disease. Neurology 1997; 49(3): 794-797.

Lopez OL, Smith G, Becker JT et al. The psychotic phenomenon in probable Alzheimer's disease: a positron emisson tomography study, J Neuropsy Clin Neurosci 2001; 13: 50-55.

Lyketsos CG, Baker L, Warren A et al. Depression, delusions, and hallucinations in Alzheimer's disease: no relationship to apolipoprotein E genotype. J Neuropsychiatry Clin Neurosci 1997; 9(1): 64-67.

Lyketsos CG, Lee HB. Diagnosis and treatment of depression in Alzheimer's disease. A practical update for the clinician. Dement Geriatr Cogn Disord 2004; 17(1-2): 55-64.

Lyketsos CG, Lopez O, Jones B, Fitzpatrick AL, Breitner J, DeKosky S. Prevalence of neuropsychiatric symptoms in dementia and mild cognitive impairment: results from the cardiovascular health study. JAMA 2002; 288(12): 1475-1483.

Lyketsos CG, Olin J. Depression in Alzheimer's disease: overview and treatment. Biol Psychiatry 2002; 52(3): 243252.

Marra C, Bizzarro A, Daniele A et al. Apolipoprotein E epsilon4 allele differently affects the patterns of neuropsychological presentation in early- and late-onset Alzheimer's disease patients. Dement Geriatr Cogn Disord 2004; 18(2): 125-131.

Masliah E, Terry RD, Alford M, DeTeresa R, Hansen LA. Cortical and subcortical patterns of synaptophysinlike immunoreactivity in Alzheimer's disease. Am J Pathol 1991; 138(1): 235-246.

Mayeux R, Small SA, Tang M, Tycko B, Stern Y. Memory performance in healthy elderly without Alzheimer's disease: effects of time and apolipoprotein-E. Neurobiol Aging 2001; 22(4): 683-689.

Mayeux R, Stern Y, Ottman R et al. The apolipoprotein epsilon 4 allele in patients with Alzheimer's disease. Ann Neurol 1993; 34(5): 752-754.

Mayeux R, Stern Y, Spanton S. Heterogeneity in dementia of the Alzheimer type: evidence of subgroups. Neurology 1985; 35(4): 453-461. 
Mega MS, Lee L, Dinov ID, Mishkin F, Toga AW, Cummings JL. Cerebral correlates of psychotic symptoms in Alzheimer's disease. J Neurol Neurosurg Psychiatry 2000; 69(2): 167-171.

Menzel HJ, Kladetzky RG, Assmann G. Apolipoprotein E polymorphism and coronary heart disease. Atherosclerosis 1983; 3: 310-315.

Morris MC, Scherr PA, Hebert LE, Glynn RJ, Bennett DA, Evans DA. Association of incident Alzheimer disease and blood pressure measured from 13 years before to 2 years after diagnosis in a large community study. Arch Neurol 2001; 58(10): 1640-1646.

Mosconi L, Herholz K, Prohovnik I et al. Metabolic interaction between ApoE genotype and onset age in Alzheimer's disease: implications for brain reserve. $\mathrm{J} \mathrm{Neu-}$ rol Neurosurg Psychiatry 2005; 76(1): 15-23.

Mosconi L, Nacmias B, Sorbi S et al. Brain metabolic decreases related to the dose of the ApoE e4 allele in Alzheimer's disease. J Neurol Neurosurg Psychiatry 2004; 75(3): 370-376.

Murphy GM Jr, Taylor J, Kraemer HC, Yesavage J, Tinklenberg JR. No association between apolipoprotein E epsilon 4 allele and rate of decline in Alzheimer's disease. Am J Psychiatry 1997; 154(5): 603-608.

Nacmias B, Piccini C, Bagnoli S et al. Brain-derived neurotrophic factor, apolipoprotein $\mathrm{E}$ genetic variants and cognitive performance in Alzheimer's disease. Neurosci Lett 2004; 367(3): 379-383.

Nagy Z, Esiri MM, Jobst KA et al. Influence of the apolipoprotein E genotype on amyloid deposition and neurofibrillary tangle formation in Alzheimer's disease. $\mathrm{Neu}$ roscience 1995; 69(3): 757-761.

Namba Y, Tomonaga M, Kawasaki H, Otomo E, Ikeda $\mathrm{K}$. Apolipoprotein E immunoreactivity in cerebral amyloid deposits and neurofibrillary tangles in Alzheimer's disease and kuru plaque amyloid in Creutzfeldt-Jakob disease. Brain Res 1991; 541(1): 163-166.

Naslund J, Haroutunian V, Mohs R et al. Correlation between elevated levels of amyloid beta-peptide in the brain and cognitive decline. JAMA 2000; 283(12): 15711577.

Newman AB, Fitzpatrick AL, Lopez O et al. Dementia and Alzheimer's disease incidence in relationship to cardiovascular disease in the Cardiovascular Health Study cohort. J Am Geriatr Soc 2005; 53(7): 1101-1107.

Nowotny P, Hinrichs AL, Smemo S et al. Association studies between risk for late-onset Alzheimer's disease and variants in insulin degrading enzyme. Am J Med Genet B Neuropsychiatr Genet 2005; 136(1): 62-68.
O'Hara R, Yesavage JA, Kraemer HC, Mauricio M, Friedman LF, Murphy GM Jr. The APOE epsilon4 allele is associated with decline on delayed recall performance in community-dwelling older adults. J Am Geriatr Soc 1998; 46(12): 1493-1498.

Olin D, MacMurray J, Comings DE. Risk of late-onset Alzheimer's disease associated with BDNF C270T polymorphism. Neurosci Lett 2005; 381(3): 275-278.

Panza F, D'Introno A, Colacicco AM et al. Cognitive frailty: Predementia syndrome and vascular risk factors. Neurobiol Aging 2005. published online Jul 13.

Papassotiropoulos A, Wollmer MA, Tsolaki M et al. A cluster of cholesterol-related genes confers susceptibility for Alzheimer's disease. J Clin Psychiatry 2005; 66(7): 940-947.

Perez-Madrinan G, Cook SE, Saxton JA et al. Alzheimer disease with psychosis: excess cognitive impairment is restricted to the misidentification subtype. Am J Geriatr Psychiatry 2004; 12(5): 449-456.

Plassman BL, Breitner JC. Apolipoprotein E and cognitive decline in Alzheimer's disease. Neurology 1996; 47(2): 317-320.

Qiu C, Winblad B, Fratiglioni L. The age-dependent relation of blood pressure to cognitive function and dementia. Lancet Neurol 2005; 4(8): 487-499.

Ramachandran G, Marder K, Tang M et al. A preliminary study of apolipoprotein E genotype and psychiatric manifestations of Alzheimer's disease. Neurology 1996; 47(1): 256-259.

Reiss AB. Cholesterol and apolipoprotein E in Alzheimer's disease. Am J Alzheimers Dis Other Demen 2005; 20(2): 91-96.

Riley KP, Snowdon DA, Markesbery WR. Alzheimer's neurofibrillary pathology and the spectrum of cognitive function: findings from the Nun Study. Ann Neurol 2002; 51(5): 567-577.

Roses AD. Apolipoprotein E affects the rate of Alzheimer disease expression: beta-amyloid burden is a secondary consequence dependent on APOE genotype and duration of disease. J Neuropathol Exp Neurol 1994; 53(5): 429-437.

Roses AD. Apolipoprotein E alleles as risk factors in Alzheimer's disease. Annu Rev Med 1996; 47. 387-400.

Rossor MN, Iversen LL, Reynolds GP, Mountjoy CQ, Roth M. Neurochemical characteristics of early and late onset types of Alzheimer's disease. Br Med J (Clin Res Ed) 1984; 288(6422): 961-964.

Rossor MN. Molecular pathology of Alzheimer's disease. J Neurol Neurosurg Psychiatry 1993; 56(6): 583-586. 
Sakamoto S, Matsuda H, Asada T et al. Apolipoprotein E genotype and early Alzheimer's disease: a longitudinal SPECT study. J Neuroimaging 2003; 13(2): 113-123.

Saunders AM, Strittmatter WJ, Schmechel D et al. Association of apolipoprotein E allele epsilon 4 with lateonset familial and sporadic Alzheimer's disease. Neurology 1993; 43(8): 1467-1472.

Scarmeas N, Brandt J, Albert M et al. Association between the APOE genotype and psychopathologic symptoms in Alzheimer's disease. Neurology 2002; 58(8): 11821188.

Schneider LS, Dagerman KS. Psychosis of Alzheimer's disease: clinical characteristics and history. J Psychiatr Res 2004; 38(1): 105-111.

Slooter AJ, Cruts M, Kalmijn S et al. Risk estimates of dementia by apolipoprotein E genotypes from a population-based incidence study: the Rotterdam Study. Arch Neurol 1998; 55(7): 964-968.

Soininen H, Kosunen O, Helisalmi S et al. A severe loss of choline acetyltransferase in the frontal cortex of Alzheimer patients carrying apolipoprotein epsilon 4 allele. Neurosci Lett 1995; 187(2): 79-82.

Soininen HS, Riekkinen PJ Sr. Apolipoprotein E, memory and Alzheimer's disease. Trends Neurosci 1996; 19(6): 224-228.

Spalletta G, Baldinetti F, Buccione I et al. Cognition and behaviour are independent and heterogeneous dimensions in Alzheimer's disease. J Neurol 2004; 251(6): 688695.

Spalletta G, Bernardini S, Bellincampi L et al. Delusion symptoms are associated with ApoE $\varepsilon 4$ allelic variant at the ersly stage of Alzheimer's disease with late onset. Eur J Neur; [in press].

Staff RT, Shanks MF, Macintosh L, Pestell SJ, Gemmell HG, Venneri A. Delusions in Alzheimer's disease: spet evidence of right hemispheric dysfunction. Cortex 1999; 35(4): 549-560.

Stern Y, Brandt J, Albert M et al. The absence of an apolipoprotein epsilon4 allele is associated with a more aggressive form of Alzheimer's disease. Ann Neurol 1997; 41(5): 615-620.

Strittmatter WJ, Weisgraber KH, Huang DY et al. Binding of human apolipoprotein $\mathrm{E}$ to synthetic amyloid beta peptide: isoform-specific effects and implications for lateonset Alzheimer disease. Proc Natl Acad Sci U S A 1993; 90(17): 8098-8102.

Sultzer DL, Brown CV, Mandelkern MA et al. Delusional thoughts and regional frontal/temporal cortex metabolism in Alzheimer's disease. Am J Psychiatry 2003; 160(2): 341-349.

Sultzer DL, Mahler ME, Mandelkern MA et al. The relationship between psychiatric symptoms and regional cortical metabolism in Alzheimer's disease. J Neuropsychiatry Clin Neurosci 1995; 7(4): 476-484.

Terry RD, Masliah E, Salmon DP et al. Physical basis of cognitive alterations in Alzheimer's disease: synapse loss is the major correlate of cognitive impairment. Ann Neurol 1991; 30(4): 1118-1119.

Terry RD. Cell death or synaptic loss in Alzheimer disease. J Neuropathol Exp Neurol 2000; 59(12): 572-580.

Utermann G, Kindermann I, Kaffarnik H, et al. Apolipoprotein E phenotypes and hyperlipidemia, Hum Genet 1984; 65: 232-236.

Vogel T, Verreault R, Kaltenbach G, Berthel M. [Hypertension and Alzheimer's disease]. Presse Med 2005; 34(11): 809-812.

Wahlund LO, Julin P, Lannfelt L, Lindqvist J, Svensson L. Inheritance of the ApoE epsilon4 allele increases the rate of brain atrophy in dementia patients. Dement Geriatr Cogn Disord 1999; 10(4): 262-268.

West MJ. Regionally specific loss of neurons in the aging human hippocampus. Neurobiol Aging 1993; 14(4): 287-293.

Wilson RS, Schneider JA, Barnes LL et al. The apolipoprotein E epsilon 4 allele and decline in different cognitive systems during a 6-year period. Arch Neurol 2002; 59(7): 1154-1160.

Wisniewski T, Frangione B. Apolipoprotein E: a pathological chaperone protein in patients with cerebral and systemic amyloid. Neurosci Lett 1992; 135: 235-238.

Yasar S, Corrada M, Brookmeyer R, Kawas C. Calcium channel blockers and risk of AD: the Baltimore Longitudinal Study of Aging. Neurobiol Aging 2005; 26(2): 157-163.

Zekanowski C, Religa D, Graff C, Filipek S, Kuznicki J. Genetic aspects of Alzheimer's disease. Acta Neurobiol Exp (Wars) 2004; 64(1): 19-31.

Address for correspondence:

Gianfranco Spalletta,

IRCCS Fondazione Santa Lucia

Laboratorio di Neurologia Clinica e Comportamentale

Via Ardeatina, 306 - 00179 Rome - Italy

Tel. 0039-0651501575; Fax: 0039-0651501388

E-mail: g.spalletta@hsantalucia.it

ITALY 